\title{
Clinical Profile of Paediatric Cataract and Surgery in a Tertiary Eye Care Centre, Nepal
}

\author{
Shrestha UD', Shrestha MK² \\ ${ }^{1}$ Dr. Ujjowala Devi Shrestha, MBBS, MD, Paediatric Ophthalmologist and Assistant Professor (NAMS), ${ }^{2}$ Mohan Krishna \\ Shrestha, MPH, PhD Scholar (TU). Both from the Tilganga Institute of Ophthalmology, Gaushala, Kathmandu, Nepal.
}

Address for correspondence: Dr. Ujjowala Devi Shrestha, E-mail: ujjowala@gmail.com

\begin{abstract}
Introduction: Paediatric cataract is the opacification of lens and its capsule in children below 14 years of age. The management of paediatric cataract is lens aspiration with or without anterior vitrectomy, with or without intra-ocular lens implantation. The objective was to present the profile of pediatric cataract of operated eyes in children $\leq 14$ years. Materials and Methods: This was a descriptive study in a hospital setting. A review of pediatric cataract cases operated between November 2007 and June 2009 in Tilganga Institute of Ophthalmology (TIO), a tertiary eye care centre in Nepal was carried out. The personal profile, preoperative and intra-operative details were noted. In the statistical analysis $p$ value less than 0.05 is considered as significant. Results: A total of 175 eyes of 132 children had presented during study. The sex ratio was 1.6 male per female with mean age of 6.7 years (SD \pm 4.3$)$. About one-third $(32 \%)$ presented within the age of three years where as more than two-fifths (46\%) presented at the age eight years and above. Seventy two cases were collected through door to door enumeration and screening clinics for children. The proportion of cataract was higher in males than in females $(P>0.05)$. Visual acuity ranged from $6 / 18$ to follows light. Conclusion: Nearly half of the paediatric cataract had presented after the age of eight years mainly from hilly region through the screening program. Most of the pediatric cataract cases presented with the whitish pupillary reflex with more than two-thirds of visual acuity of less than 3/60. The most common type of the cataract surgery performed was lens aspiration with anterior vitrectomy with lens implantation. The earlier the surgery better is the visual prognoses. Hence, community screening through as door to door screening and one day screening clinics will help for early referral and earlier surgery to reduce visual disabilities due to paediatric cataract.
\end{abstract}

Key words: Cataract, Cataract surgery, Childhood blindness, Nepal

\section{Introduction}

$P$ aediatric cataract is the opacification of the lens and its capsule in children below 14 years of age. Childhood blindness is one of the priority eye diseases within the disease-control strategy of the 'VISION 2020' initiative ${ }^{1}$. Dealing with cataract in children is important. Earlier only the adult age related cataracts were operated by the ophthalmologists to reduce the global blindness. Today, by operating on congenital cataract cases, childhood blindness rates could be reduced and the quality of life of children could also be improved. It is a cost-effective intervention, second only to immunization to prevent vaccine-related diseases ${ }^{2}$. Cataract constitutes $24.8 \%, 43.8 \%$ and $29.4 \%$ of childhood blindness in highincome, middle-income and low-income countries respectively. There are around 190,000 blind children suffering from cataract worldwide 2 . More than $40 \%$ of cataracts in children were due to preventable causes in these studies.

In Nepal, the exact number of children suffering from paediatric cataract is still unknown. Therefore, child health and eye care facilities are in focus in the tertiary eye care center like Tilganga Institute of Ophthalmology (TIO). Hence the study of childhood cataract in TIO would be useful for early screening, detection and service of eye care among children. In the villages of Nepal, very few mothers and people in the village community are aware about the importance of early detection, and treatment of the paediatric cataract. Paediatric eye care services at $\mathrm{TIO}$ are provided by paediatric ophthalmologists. In the community level the local volunteers and ophthalmic technician provide the door to door screening for the paediatric age group. 
Himalayan Childhood Blindness Alleviation and Eye Health Initiative project have focused on the service delivery at the community level through door to door screening. The community ophthalmic services and eye screening are playing vital role in paediatric eye care through early detection, counseling and referring children with cataract. Those children identified with the paediatric cataract are referred to tertiary eye care center, TIO.

\section{Materials and Methods}

This is a descriptive study. Children $\leq 14$ years of age visiting TIO were the study population. The cataract cases operated at TIO between November 2007 and June 2009 were included. Only one paediatric ophthalmologist examined children and operated eyes with paediatric cataract.

In children greater than 5 years vision of each eye was assessed with the help of Snellen's distant vision 'E chart'. If a child was unable to recognize the symbol in the top line of the chart kept at 6-meter distance, we asked him/her to count the number of fingers of the examiner at 3-, 2- and 1-meter distances. In younger children vision was noted as whether the child followed the light or not. The best corrected visual acuity was noted. Children were examined by paediatric ophthalmologists using the slit lamp bio-microscope. The pupils were dilated with one drop of tropicamide (1\%). The posterior segment of the eye was evaluated with the help of an indirect ophthalmoscope and a +20 Dioptre Volk Lens. Ultrasound B scans was done in those cases when there was absence of fundal glow and indirect ophthalmoscopy was not possible. All the children underwent biometry under general anaesthesia. The surgical procedure for the paediatric cataract was lens aspiration, posterior capsulotomy and anterior vitrectomy, with or without intra-ocular lens implantation. The intraoperative details were retrieved from the operation case records. The personal details of every child included his/her age, gender, and area of residence. The ocular details included the principal diagnosis, eye involved, type of cataract, preoperative vision, operative steps and complications (if any). Collected data were entered in Microsoft Excel and analysis was done in Statistical Package for Social Science (SPSS) version 11.5. The ethical approval was granted by Institution Review Committee of TIO.

\section{Results}

One hundred and thirty two children with 175 eyes were operated during study period. The mean age of the participants was 6.7 years $(S D \pm 4.3)$ with range of one month to 14 years at the time of surgery. The sex ratio was 1.6 male per female (Table 1a). About one-third (32\%) presented within the age of three years where as more than two-fifths (46\%) presented at the age eight years and above.

Table 1a:Age and gender distribution of cataracts

\begin{tabular}{|l|c|c|c|c|c|c|}
\hline \multicolumn{2}{|l|}{ Description } & \multicolumn{3}{|l|}{ Age in years } & \multirow{2}{*}{ Total } & \multirow{2}{*}{ *p value } \\
\hline Sex & & $\mathbf{0 - 3}$ & $\mathbf{> 3 - 7}$ & $\mathbf{> 7 - 1 4}$ & & \\
\hline \multirow{2}{*}{ Female } & $\mathrm{N}$ & 18 & 12 & 21 & 51 & \\
\cline { 2 - 6 } & $\%$ & 35.3 & 25.5 & 41.2 & 100.0 & \\
\hline \multirow{2}{*}{ Male } & $\mathrm{N}$ & 24 & 18 & 39 & 81 & \multirow{2}{*}{$>0.05$} \\
\cline { 2 - 6 } & $\%$ & 29.6 & 22.2 & 45.5 & 100.0 & \\
\hline \multirow{2}{*}{ Total } & $\mathbf{N}$ & $\mathbf{4 2}$ & $\mathbf{3 0}$ & $\mathbf{6 0}$ & $\mathbf{1 3 2}$ & \\
\cline { 2 - 6 } & $\%$ & $\mathbf{3 1 . 8}$ & $\mathbf{2 2 . 7}$ & $\mathbf{4 5 . 5}$ & $\mathbf{1 0 0 . 0}$ & \\
\hline
\end{tabular}

${ }^{*} p$ value $=0.714$ and chi-square value $=0.674$

Seventy two cases (42.3\%) were collected through door to door enumeration and screening clinics for children (Table 1b).

Table1b: Gender and case finding status

\begin{tabular}{|l|c|c|c|c|c|}
\hline \multicolumn{2}{|l|}{ Description } & \multicolumn{2}{|c|}{ Sex } & \multirow{2}{*}{ Total } & \multirow{2}{*}{ *p value } \\
\hline \multicolumn{2}{l|l}{ Case findings } & Female & Male & & \\
\hline \multirow{2}{*}{ Self reported } & $\mathrm{N}$ & 18 & 42 & 60 & \\
\cline { 2 - 5 } & $\%$ & 35.3 & 51.9 & 100.0 & \multirow{2}{*}{$>0.05$} \\
\hline \multirow{2}{*}{ Screening } & $\mathrm{N}$ & 33 & 39 & 72 & \\
\cline { 2 - 5 } & $\%$ & 64.7 & 48.1 & 100.0 & \\
\hline \multirow{2}{*}{ Total } & $\mathbf{N}$ & $\mathbf{5 1}$ & $\mathbf{8 1}$ & $\mathbf{1 3 2}$ & \\
\cline { 2 - 5 } & $\%$ & $\mathbf{3 7 . 7}$ & $\mathbf{6 2 . 3}$ & $\mathbf{1 0 0 . 0}$ & \\
\hline
\end{tabular}

${ }^{*} p$ value $=0.063$, chi square $=3.461$

Seventy four (45.5\%) children (8 years and above) with cataract were operated in late ages. Children were from the 45 districts of Nepal $(60 \%$ of the total districts in Nepal), from eastern to far western development region of Nepal. Among them 35 children with paediatric cataract $(20 \%$ total cases) were presented from intervention districts (Bhaktapur, Dhading, Makawanpur, Nuwakot, Rasuwa and Sindhupalchok) through door to door enumeration. In addition to that 37 cases (21.1\%) were from Kathmandu and Lalitpur districts screened through screening clinics. Based on ethnicity, sixty children (45.5\%) were Mongolian forty one (31.1\%) were Brahmin, (Table 2).

Table 2: Ethnicity of patients

\begin{tabular}{|l|c|c|}
\hline Ethnicity & Number & Percentage \\
\hline Mongolian & 60 & 45.5 \\
\hline Brahmin & 41 & 31.1 \\
\hline Madheshi & 12 & 9.1 \\
\hline Chhetri & 10 & 7.6 \\
\hline Others & 9 & 6.8 \\
\hline
\end{tabular}

For paediatric cataract surgery, patients travelled from all three regions (Mountains, Hills and Terai) of Nepal. Eighty two patients (62.1\%) were from Hilly 
region. Thirty one children (23.5\%) were from Terai region. Rest of the nineteen patients (14.4\%) was from mountainous region (Table 3 ).

Table 3: Patients from different regions

\begin{tabular}{|l|c|c|}
\hline Regions & Number & Percentage \\
\hline Hill & 82 & 62.1 \\
\hline Mountain & 19 & 14.4 \\
\hline Terai & 31 & 23.5 \\
\hline Total & $\mathbf{1 3 2}$ & $\mathbf{1 0 0 . 0}$ \\
\hline
\end{tabular}

Based on religion, seventy children (53.0\%) were Hindu and sixty (45.5\%) were Buddhist (Table 4)

Table 4: Religion of patients

\begin{tabular}{|l|c|c|}
\hline Region & Number & Percentage \\
\hline Hindu & 70 & 53.0 \\
\hline Buddhist & 60 & 45.5 \\
\hline Muslim & 2 & 1.5 \\
\hline Total & $\mathbf{1 3 2}$ & $\mathbf{1 0 0}$ \\
\hline
\end{tabular}

The clinical presentation of children with paediatric cataract was white pupillary reflex, nystagmus, and strabismus. White pupillary reflex was noted in 158 (79.0\%) eyes. Nystagmus was noted in 26 eyes. Strabismus was noted in 16 eyes. Eleven children had esotropia. Five children had exotropia. Twenty five eyes had more than one clinical feature (Table 5).

Table 5: Clinical presentation of pediatric cataract eyes

\begin{tabular}{|l|c|c|}
\hline Description & Number & Percentage \\
\hline White pupillary reflex & 158 & 79.0 \\
\hline Nystagmus & 26 & 13.0 \\
\hline Strabismus & 16 & 8.0 \\
\hline
\end{tabular}

The patients operated for the paediatric cataract had different types of congenital cataracts. Sixty seven (38.3\%) were lamellar cataract. Traumatic cataract was ten (5.7\%). Other types of cataract were 98 (56.0\%). Those were anterior polar, anterior subcapsular cataract, congenital nuclear cataract, complicated cataracts, membranous, partially absorbed, posterior lenticonus, posterior polar, posterior subcapsular, subluxated, total, sutural and unspecified cataracts.

Table 6: Pre-operative visual acuity

\begin{tabular}{|l|c|c|}
\hline Visual acuity & Number & Percentage \\
\hline $6 / 6-6 / 18$ & 8 & 8.5 \\
\hline$<6 / 18-6 / 60$ & 18 & 19.1 \\
\hline$<6 / 60-3 / 60$ & 3 & 3.2 \\
\hline$<3 / 60$ & 65 & 69.1 \\
\hline Total & $\mathbf{9 4}$ & $\mathbf{1 0 0 . 0}$ \\
\hline
\end{tabular}

Visual acuity of children with paediatric cataract ranged from better than $6 / 18$ to follows light as shown in (Table 6). In $69.1 \%$ of the eyes visual acuity was less than $3 / 60$. So, visual acuity was worse than $6 / 60$ in 72.3 $\%$ at the time of presentation. In 81 eyes the status of the visual acuity was difficult to assess due to child age below five years.

According to the laterality, paediatric cataract can be either unilateral or bilateral. Eighty nine cases were unilateral where as forty three cases were bilateral. (Table7).

Table 7: Laterality

\begin{tabular}{|l|c|c|}
\hline Description & Number & Percentage \\
\hline Unilateral & 89 & 67.4 \\
\hline Bilateral & 43 & 32.6 \\
\hline
\end{tabular}

Biometry was performed in all the eyes under general anesthesia. The surgical procedure performed for paediatric cataract surgery at tertiary eye centre was lens aspiration, posterior capsulotomy and anterior vitrectomy, with or without intra-ocular lens implantation. Anterior vitrectomy was performed in children less than 8 years. In bilateral cases, intra-ocular lens was implanted in children greater than two years of age. In unilateral cases intra-ocular lens was implanted irrespective of age. Ninety eyes (51.4\%) underwent the lens aspiration with anterior vitrectomy with intraocular lens implantation. Rest of the patients underwent lens aspiration only, lens aspiration with intra-ocular lens implantation, and lens aspiration with anterior vitrectomy (Table 8).

Table 8: Types of surgery performed in eyes $(n=175)$

\begin{tabular}{|l|c|c|}
\hline \multicolumn{1}{|c|}{ Description } & Number & Percentage \\
\hline $\begin{array}{l}\text { Lens aspiration+ anterior } \\
\text { vitrectomy + posterior } \\
\text { chamber intra-ocular lens } \\
\text { implantation (PCIOL) }\end{array}$ & 90 & 51.4 \\
\hline $\begin{array}{l}\text { Lens aspiration+ anterior } \\
\text { vitrectomy }\end{array}$ & 50 & 28.6 \\
\hline Lens aspiration with PCIOL & 32 & 18.3 \\
\hline Lens aspiration & 3 & 1.7 \\
\hline
\end{tabular}

None of the patients had per-operative complications.

\section{Discussion}

Tilganga Institute of Ophthalmology has been providing the child eye health care services since its establishment. However, to promote the community participation and coverage of services at community level, the door to door screening and one day screening 
eye clinics in within peripheral of Kathmandu valley for the children. This is the first attempt to review pediatric cataract after launching the project. Seventy two cases were collected through door to door enumeration and screening clinics for children. Low socio economic status of study population, lack of eye care services in the past, and lack of awareness in the community were perhaps responsible for this higher frequency of childhood cataract in our study.

Recording visual acuity in children is big challenge in young children. Inability to record visual status has been mentioned in other publications as well ${ }^{5,6}$. In this study, the status of the visual acuity was difficult to assess in 81 eyes of children below five years. Inability to assess vision for many operated cases was due to poor cooperation of young children. Making the eye unit children friendly, providing assessment kits and training the staff in vision assessment using toys are recommended ${ }^{3}$.

The number of cataract surgery was higher in boys than in girls like in Danish study ${ }^{7}$. The number of boy child was 81 compared to 51 for the girl child. This could be explained by that boy child are more privileged than the girl child. The female child has less access to eye care services. Thus the girl child with pediatric cataract may have less opportunity to attend the hospitals than the boy child.

Late presentation, especially for congenital cataracts, is a matter of concern. In this study about onethird (32\%) presented within the age of three years where as more than two-fifths (46\%) presented at the age eight years and above. In Nepal in one of the previous studies, the mean age of presentation was 6.2 years ${ }^{8}$.

Strengthening primary eye care and adopting the community eye care approach would help in early detection, proper counseling and timely management. Late presentation has poor visual prognoses following cataract surgeries. Better follow-ups and assessments of visual function of all children operated for cataract are recommended. They will lead to detection and prevention of eye complications in these children ${ }^{9}$ However there are still lot of challenges for the pediatric ophthalmologist ${ }^{10}$

The incidence of bilateral cataracts was more than unilateral cataracts in a study in Denmark ${ }^{8}$. Eighty nine cases were unilateral whereas forty three cases were bilateral in this study. The unilateral cataract in children without significant history of trauma should be examined periodically to detect cataract in the fellow eye.
Paediatric cataracts are usually subdivided by morphology. The most common type of pediatric cataract is the zonular cataract, which is characterized by an opacification of a discrete region of the lens. This type includes nuclear, lamellar, sutural, and capsular cataracts. In this study too, the most common type of cataract was lamellar cataract ${ }^{11}$

In this study, mostly Hindus and Mongolians from hilly region presented with paediatric cataract. The prevalence of paediatric cataracts has been reported to range from 1.2 to 6 cases per 10,000 births. This range probably reflects the ethnic and racial diversities of the study populations, as well as different methodologies of ascertainment ${ }^{12,13}$.

\section{Conclusion}

Nearly half of the paediatric cataract had late presentation after the age of eight and above. More than half of the patients were collected through the screening. Visual acuity of children with paediatric cataract ranged from better than $6 / 18$ to follows light. More than two-thirds of cases were having visual acuity of less than $3 / 60$ in cataractous eyes. Most of the paediatric cataract cases present with the whitish pupillary reflex. Most common type of the congenital cataract was the lamellar cataract. The most common type of the cataract surgery performed was lens aspiration with anterior vitrectomy with posterior chamber intra-ocular lens implantation ( $\mathrm{PCIOL})$.The earlier the surgery better is the visual prognoses. Hence, community screening will help for early referral and earlier surgery. The community ophthalmology approach such as door to door screening and one day screening clinics could complement clinicians' efforts to reduce visual disabilities due to cataract in children.

\section{Acknowledgements: None \\ Funding: None \\ Conflict of Interest: None \\ Permission from IRB: Yes}

\section{References}

1. World Health Organization. Global initiative for the elimination of avoidable blindness. 1997, Accessed on 10 November 2010 http://whqlibdoc.who.int/ hq/1997/WHO_PBL_97.61_Rev.1.pdf.

2. Khandekar R, Sudhan A, Jain BK et al. Pediatric cataract and surgery outcomes in Central India: A hospital based study. Indian J Med Sci 2007;61:15-22.

3. Dandona R, Dandona L. Childhood blindness in India: A population based perspective. $\mathrm{Br} J$ Ophthalmol 2003;87:263-5. 
4. Wilson ME Jr, Saunders RA, Trivedi RH. Pediatric Ophthalmology; Current Thought and a Practical Guide, 1st edi. Germany, Springer. 2009:325- 344.

5. Pavlovic S. Cataract surgery in children. Med Pregl 2000;53:257-61.

6. Lee YC, Kim HS. Clinical symptoms and visual outcome in patients with presumed congenital cataract. I Pediatr Ophthalmol Strabismus 2000;37:219-24.

7. Haargaard B, Wohlfahrt J, Fledelius $\mathrm{HC}$ et al. A nationwide Danish study of 1027 cases of congenital/infantile cataracts: Etiological and clinical classifications. Ophthalmology 2004;111:2292-98.

8. Thakur J, Reddy H, Wilson ME Jr, et al. Pediatric cataract surgery in Nepal. J Cataract Refract Surg 2004;30:1629-35.
9. Rahi JS, Dezateux C. National cross sectional study of detection of congenital and infantile cataract in the United Kingdom: Role of childhood screening and surveillance. The British Congenital Cataract Interest Group. BMJ 1999;318:36-5.

10. Morgan KS. Cataract surgery and intraocular lens implantation in children. Curr Opin Ophthalmol 1993;4:54-60.

11. Hiles DA. Infantile cataracts. PediatrAnn 1983;12:55673.

12. Kohler L, Stigmar G. Vision screening of four-year old children. Acta Paediatr Scand 1973; 62:17-27.

13. Stoll C, Alebik Y, Dott B, Roth MP. Epidemiology of congenital eye malformations in 131,760 consecutive births. Ophthalmic Pediatr Genet 1993; 30:433-35.

\section{How to cite this article?}

Shrestha UD, Shrestha MK. Clinical Profile of Paediatric Cataract and Surgery in a Tertiary Eye Care Centre, Nepal. J Nepal Paediatr Soc 2012;32(1):14-18. 